\title{
A41 ALTERINATE
}

PLATFORM

\section{Computer Programming and Basic Education}

Jaco Malan

\section{Abstract}

In our world today, many basic skills are taught to the youth-skills such as mathematics, physical sciences and language, just to name a few. In this paper, I will explore a few reasons why computer programming should be added to this list.

\section{Keywords}

computer programming, basic education 


\section{Introduction}

We live in a world where basic education has become a human right. This naturally leads to a more probing question concerning which subjects should be considered 'basic education'. Basic skills such as languages are taught to children so that they may start their adult lives with all the skills they need to operate effectively in modern society.

The 2011 version of the International Standard Classification of Education, Level 1 (ISCED 1) defines the skills taught to children during the primary education stage of their school career (nine levels of education). Levels 0 to 3 describe school education from kindergarten to the end of high school.

In the early days, education mostly consisted of parents transferring the knowledge they had to their children. For the sake of argument, in this discussion, we will be considering this as the most basic form of education. It is in this that we can find a definition of what exactly we mean by 'education'. 'Education is the social institution through which a society teaches its members the skills, knowledge, norms, and values they need to learn to become good, productive members of their society' (Anonymous 2016).

In this paper, a few reasons as to why computer programming should be considered a skill that members of a society need to become 'good and productive' will be explored.

\section{General discussion}

Imagine for a moment a hypothetical hermit named Joe. Joe has extreme paranoia and often talks about how the government is spying on the people through their technology. He does not own a single thing that utilises electricity. His house, located on the outskirts of town, is shielded from radiation and he does not allow anyone with an electronic device into his home.

If one day, Joe decides to buy a car, he will face several issues. The first problem he would probably encounter is in selecting a car to buy. Most cars produced today have electronic devices built in for everything from speed control to automatic gear shifting and engine performance control. Well, let us suppose that Joe does manage to find a car without integrated electronics. The next problem he would face is securing the money required to purchase the car. The average compact car costs about R350k 
$( \pm \$ 25,000)$. For the sake of argument, we will call this car a Hermit ${ }^{\mathrm{tw}}$ Compact Car. Assuming Joe does not have a job ${ }^{1}$, he would need to take out a loan. By law in South Africa, a credit provider has the right to use any criteria they deem necessary for financial risk management and strategy (South African Parliament, National Credit Act 2006).

This usually means doing a 'credit check' on the applicant to determine if they would be able to repay the loan, were they to receive one. Most credit checks are done through a credit agency, and they usually use a computer database to retrieve information about an applicant and disclose it to the credit provider. An applicant has the right to decline a credit check, but as mentioned previously, a credit provider may use that against you. In other words, if you do not agree to a credit check, you cannot receive a loan from a registered credit provider. This is a critical problem for Joe. He is much too paranoid to agree to a credit check and as a consequence, he will have a hard time obtaining a loan.

It should be evident from the case of Joe the Hermit that it is extremely difficult to do even the most basic of transactions in modern society as it requires interacting with a computer system. Now, let us think back to our most basic form of education. The entire purpose of our basic education system is to give members of society the required skills to be functional. Joe is, by all accounts, not a functioning member of society. This is because of his paranoia, but more specifically, it is a result of his inability to interact with a computer system.

This is also the case when one considers someone unable to read or do mathematics. In this very way, computer science and the skills related to it are very similar to the other subjects of basic education. For this reason, this paper aims to promote programming and computer science as compulsory for basic education.

\section{Programming language suggestions}

There are several programming languages of varying difficulties that are suitable to be taught to a wide range of age groups, one of the most popular among them being Python. Python is used in everything from scientific research to 3D modelling and animation. This, in combination with its relatively elementary syntax, makes it a

1 For Joe to have a job, he would need to somehow collect a pay cheque. For this to happen, he needs to interact with the banking system. This inevitably results in a computer becoming involved, so we assume he does not have a job. 
prime candidate to use for teaching the concept of programming. At more advanced stages, languages belonging to the $\mathrm{C} / \mathrm{C}++$ syntax family are probably good choices, to name but a few: Java, C, C++, C\#, Kotlin, JavaScript, Rust, etc.

\section{Final words}

This paper aimed to advocate for the requirement that children be taught programming as part of their basic education. From the above discussion, Evans Data Corporation reported that about $3.8 \mathrm{~m}$ people had jobs requiring computer programming in the United States (PK 2020). This constitutes about 1.12\% of the United States population. This figure is much lower than the mathematical literacy rate. This is just one of many examples of how illiterate people are about computer programming. In my opinion, this issue needs to be addressed with extreme urgency. 


\section{References}

Anonymous. 2016. '16.1 A Brief History of Education in the United States'. Sociology

- Understanding and Changing the Social World. University of Minnesota Libraries Publishing: 598. (By request of the original publisher, the name of the author was removed from the book.)

South African Parliament. 2006. National Credit Act. 60(2). 